\title{
Recycling of Non-metallic Residue from Waste Printed Circuit Boards to Produce Interlocking Concrete Blocks
}

\author{
Sawitri Pianchaiyaphum, Suphaphat Kwonpongsagoon, Premrudee Kanchanapiya, and Chakrapan \\ Tuakta
}

\begin{abstract}
The process of copper recovery from waste printed circuit board has generated large amounts of non-metallic fraction (NMF) residue. In this research, the residue was recycled as a substitute for fine aggregates at $0 \%$, $5 \%, 10 \%, 15 \%$, and $20 \%$ to produce interlocking concrete blocks. Properties of the interlocking concrete blocks produced in this study, such as density, water absorption, compressive strength, were firstly examined and the selected mixes were further evaluated for the heavy metal leachability. The results indicated that the NMF residue affected physical, mechanical and chemical properties of NMF interlocking concrete block samples. When increasing NMF contents, the density and compressive strength decreased, while the water absorption increased. In the leachability results, the leaching of $\mathrm{Cu}$ decreased as cement content increased, and its concentration level was well below the Soluble Threshold Limit Concentration limit (STLC). Thus, the high content of $\mathrm{Cu}$ and all other metals embedded in the NMF material were immobilized in the interlocking concrete block specimens.
\end{abstract}

Index Terms-Interlocking concrete block, non-metallic fraction residue, recycling, waste printed circuit board

\section{INTRODUCTION}

Waste electrical and electronic equipment (WEEE) or electronic waste (e-waste) is one of the fastest growing waste streams in the world because of the advancements in electrical and electronic equipment (EEE) and consumer behavior. The massive number of EEE products have become obsolete rapidly, accelerating a significant rise in the volume of e-waste in every country. The increasing amount of such e-wastes is the major environmental concern around the world due to a wide variety of hazardous substances (i.e. heavy metals, flame retardants) contained in the EEE products. Globally, the quantity of e-waste generated has been increased at a rate of $5-10 \%$ annually, mostly occur in Asia. Around $15-20 \%$ of these e-wastes are collected and recycled, while the rest are likely to go to landfill and incineration [1]. According to the state of pollution report in 2018 by Thailand Pollution Control Department, during the

Manuscript received September 29, 2020; revised March 15, 2021.

Sawitri Pianchaiyaphum and Suphaphat Kwonpongsagoon are with the Department of Sanitary Engineering, Faculty of Public Health, Mahidol University, Bangkok, 10400, Thailand. They are also with Center of Excellence on Environmental Health and Toxicology (EHT), Bangkok, 10400,Thailand (e-mail:sawitri.ppia@gmail.com, suphaphat@hotmail.com)

Premrudee Kanchanapiya is with National Metal and Materials Technology Center, Pathum Thani, 12120, Thailand (e-mail: premrudk@mtec.or.th)

Chakrapan Tuakta is with the Department of Civil Engineering, Faculty of Engineering, Kasetsart University, Bangkok, 10900, Thailand (e-mail ctuakta@gmail.com) last ten years WEEE in Thailand has been generated approximately $3-400,000$ tons yearly [2].

Printed circuit board is a basic component in almost every type of EEE products. The waste printed circuit boards (PCBs) present a relatively small portion, about 3-6\% of the total WEEE generated [3], [4]. In general, the waste PCBs have two characterizations: 1) without attached electronic parts called printed circuit board (PCB), consisting of $28 \%$ metallic fraction (MF) and $72 \%$ non-metallic fraction (NMF) [5]; and 2) with attached components or electronic parts such as resistors, connectors, and capacitors called printed circuit board assembly (PCBA), consisting of $40 \%$ metallic fraction (MF) and 60\% non-metallic fraction (NMF) [6]. The waste PCBs generally contain a variety of metals, including precious as well as toxic metals such as gold, copper, platinum, nickel, lead, etc. According to Cayumil et al. [7], the recovery of precious metals, e.g. silver, gold, copper, and palladium from e-wastes is expected to have a significant economic impact because these precious metals present up to $80 \%$ of the total value of the entire device, and show higher concentration level compared to their natural deposit in ores. In the early days, the recycling process of waste PCBs was seriously aimed at achieving high economic benefits of precious metals recovery and environmental benefits of waste PCB recycling by ignoring the non-metallic fractions due to the complexity of recycling process and lower economic profits of such residues [8], [9]. In Thailand, waste PCB recycling industries only focus on the process of copper recovery for sale and export [10]. Most use a simple mechanical and physical process to recycle PCB and PCBA scraps which are usually crushed into small particle sizes, and copper is then separated out by shaking table. After the recycling process, copper is recovered about $20-30 \%$ and more than $60 \%$ are NMF residue which can usually be managed by landfilling and incineration [10]-[12]. However, according to Guo et al. [13], [14], incineration of the non-metallic residue is neither economical nor suitable method because of a large portion of inorganic components contained (glass fiber), giving a low combustion value, and reducing the incinerator efficiency. In addition, the incineration process has to be upgraded to prevent the formation of highly toxic substances such as polybrominated dibenzodioxins and dibenzofurans (PBDD/Fs). For general landfilling, in addition to a massive land use, it could release various toxic substances into soil and groundwater by leaching, infiltration, and vaporization of volatile compounds, such as mercury to the surrounding environment [13]. Both disposal methods represent a non-sustainable management with a loss of valuable resources. According to Europe 
WEEE directives and some researches, recycling and recovering process have therefore been recommended as a first priority and better way to handle such wastes [13]-[15].

Recently, several researchers have tried to investigate the potential application of NMF residue as a raw material in various group of products such as polymer-based and cement-based (i.e. glass fiber reinforced plastic (GFRP) products - table top and lecture chair prototype, a phenolic molding compound, mortar and concrete) [16]-[20]. Besides, one of the previous studies considering disposal of NMF in landfills using a cement-based solidification/stabilization $(\mathrm{S} / \mathrm{S})$ method revealed that the lab-scale specimens mixed with NMF derived from both PCB and PCBA types were able to immobilize heavy metals to the environment, and satisfied the standard testing method for compressive strength [11]. The study also indicated that NMF could enhance the durability characteristics of concrete products as high silica content in NMF can react well with alkali in cement and sand in the cement matrix. Therefore, it is a possibility to recycle NMF residue from waste PCBs as a substitute for fine aggregate to produce a new concrete product. However, concerning about health hazards relating to the toxic substances remaining in the NMF, the concrete product used for outdoor purposes is an interesting choice. Thus, the objective of this study is to recycle the NMF residue from waste PCBs to produce an interlocking concrete block which is classified as a non-load bearing concrete product category. Properties of the concrete blocks such as density, water absorption, compressive strength and heavy metal leachability were also examined according to the standard testing methods.

\section{MATERIALS AND METHODS}

\section{A. Materials}

1) Non-metallic residue from waste printed circuit board

The NMF residue used in this study was derived from one of the waste $\mathrm{PCB}$ recycling plants located in Ratchaburi province in Thailand. At the recycling plant, the size of PCB scraps was reduced by a grinding mill machine. After that copper was separated out using a shaking table. The remaining part is NMF residue which is dried out before storage for further treatment or disposal. Since the NMF was utilized as a substitute for fine aggregates to produce interlocking concrete blocks in this study, the differences between NMF and natural sand will be later discussed in the next section. In case of NMF, the chemical composition analyzed by X-ray fluorescence (XRF) was reported and compared to others as shown in Table I. With the same recycling technology, the main elements found in NMF residues are silicon $(\mathrm{Si})$, calcium $(\mathrm{Ca})$, bromine $(\mathrm{Br})$, aluminium (Al) whereas copper $(\mathrm{Cu})$ showed the highest concentration among heavy metals remaining in the NMF. Regarding oxide compounds, $\mathrm{SiO}_{2}, \mathrm{CaO}$ and $\mathrm{Al}_{2} \mathrm{O}_{3}$ are the most common contents found in the NMF residue.

\section{2) Sand}

Fig. 1 presents the particle size distribution of natural sand, and comparison to NMF residues. With sieve analysis, the size of sand particles used in this study ranges from 0.15 to $2.36 \mathrm{~mm}$. As seen in Fig. 1, the distribution of sand particle size was continuous and well graded, meeting the grading requirements of ASTM C33. But the NMF residues are remarkably different from sand aggregates. They are much finer than sand particles, exceeding the upper limit of ASTM C33 as also seen in Fig. 1.

\begin{tabular}{lrrrrr}
\multicolumn{5}{c}{ TABLE I: CHEMiCAL COMPOSITION OF NMF RESIDUE } \\
\hline \multirow{2}{*}{ Composition } & \multicolumn{5}{c}{ NMF (PCB) (\%wt) } \\
\cline { 2 - 6 } & This study & \multicolumn{1}{c}{$[\mathbf{1 1}]$} & {$[\mathbf{1 2}]$} & {$[\mathbf{2 1}]$} & {$[\mathbf{2 2}]$} \\
\hline Oxide & & & & & \\
$\mathrm{SiO}_{2}$ & 28.80 & 43.35 & 29.70 & $\mathrm{~N} / \mathrm{A}$ & $\mathrm{N} / \mathrm{A}$ \\
$\mathrm{CaO}$ & 11.80 & 69.15 & 13.10 & $\mathrm{~N} / \mathrm{A}$ & $\mathrm{N} / \mathrm{A}$ \\
$\mathrm{Al}_{2} \mathrm{O}_{3}$ & 9.88 & 17.31 & 6.40 & $\mathrm{~N} / \mathrm{A}$ & $\mathrm{N} / \mathrm{A}$ \\
Other oxides & $<5$ & $<10$ & $<5$ & N/A & N/A \\
Element & & & & & \\
$\mathrm{Si}$ & 12.00 & $\mathrm{ND}$ & 13.78 & 9.21 & 28.25 \\
$\mathrm{Ca}$ & 7.67 & $\mathrm{ND}$ & 8.29 & 6.90 & 28.66 \\
$\mathrm{Br}$ & 6.53 & 6.50 & 9.76 & 16.40 & 26.43 \\
$\mathrm{Al}$ & 4.66 & $\mathrm{ND}$ & 2.94 & 3.00 & 6.86 \\
$\mathrm{Cu}$ & 1.07 & 4.00 & 2.01 & 2.52 & 2.51 \\
Other metals & $<1$ & $<1$ & $<1$ & $<1$ & $<1$ \\
\hline
\end{tabular}

$\mathrm{ND}=$ Not detectable

N/A $=$ Not applicable

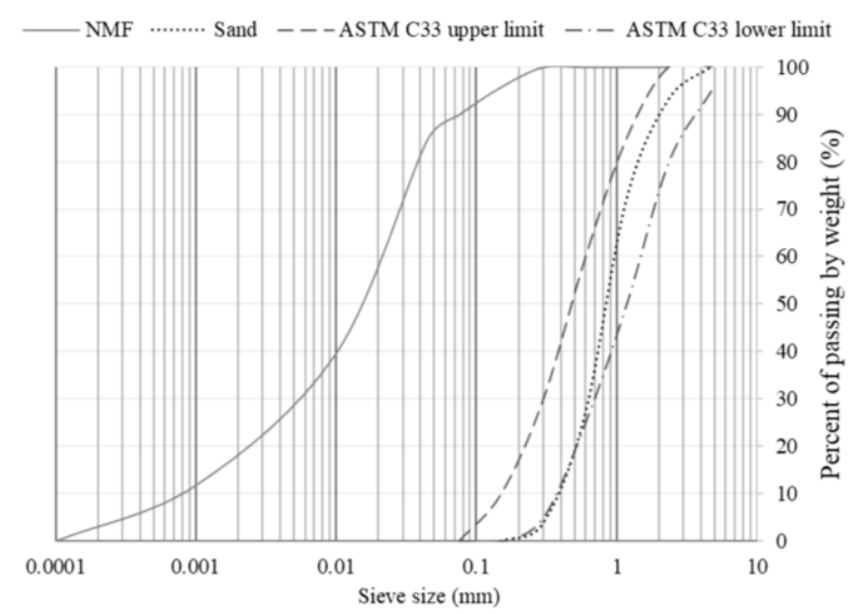

Fig. 1. Particle size distribution of natural sand and NMF residue.

The characterizations of natural sand aggregate and NMF residue are presented in Table II. It can be seen that the appearance of natural sand aggregate is smooth and rounded with brown color, while NMF residue is light green with a needle shape. The particle specific gravity of NMF residue is $32 \%$ lower than that of sand, while water absorption of NMF is higher than that of sand.

TABLE II: PhysiCAL PROPERTIES OF AGGREGATES

\begin{tabular}{lcc}
\multicolumn{2}{c}{ TABLE II: PHYSICAL PROPERTIES OF AGGREGATES } \\
\hline \multirow{2}{*}{ Physical properties } & Sand & Nggregates \\
\cline { 2 - 3 } & & \\
\hline & & \\
Visual appearance & 2.44 & 1.66 \\
$\begin{array}{l}\text { Bulk specific } \\
\text { gravity, g/cm3 }\end{array}$ & 2.48 & 1.75 \\
$\begin{array}{l}\text { Bulk specific gravity } \\
\text { (SSD), g/cm3 }\end{array}$ & 1.4 & 5.26 \\
$\begin{array}{l}\text { water absorption } \\
\text { (\%) }\end{array}$ & & \\
\hline
\end{tabular}

SSD = Saturated Surface-Dried 


\section{3) Other materials}

Other necessary materials used to produce interlocking concrete blocks include Ordinary Portland Cement (OPC) type I complying with ASTM 150, and tap water that was used to produce all interlocking concrete block mixtures and to cure the specimens.

\section{B. Methods}

\section{1) Product mix preparation and production method}

A total of five mix proportions with six replicates (30 specimens in total) were prepared at an interlocking concrete block production plant. The mix ratio of cement to fine aggregate (sand) was kept at $1: 5$ by weight, with waterto-cement $(\mathrm{w} / \mathrm{c})$ ratio of 0.5 . The $\mathrm{NMF}$ residue was used to replace fine aggregate by weight at $0 \%, 5 \%, 10 \%, 15 \%$ and $20 \%$. Table III shows the details of 5 different mix designs prepared in this study.

TABLE III: MIXTURE OF INTERLOCKING CONCRETE BLOCK PRODUCTION

\begin{tabular}{ccccc}
\hline \multirow{2}{*}{ No. } & Mix ratio & \multicolumn{2}{c}{ Aggregate $(\%)$} & \multirow{2}{*}{$\begin{array}{c}\text { W/C } \\
\text { ratio }\end{array}$} \\
\cline { 2 - 4 } & OPC/Aggregate & Sand & NMF & 0.5 \\
NMF-0 & $1: 5$ & 100 & 0 & 0.5 \\
NMF-5 & $1: 5$ & 95 & 5 & 0.5 \\
NMF-10 & $1: 5$ & 90 & 10 & 0.5 \\
NMF-15 & $1: 5$ & 85 & 15 & 0.5 \\
NMF-20 & $1: 5$ & 80 & 20 & \\
\hline
\end{tabular}

Fig. 2 shows the production of interlocking concrete blocks in this study. Each mix proportion was manually blended in a mixing bowl. The semi dry concrete mix (or no-slump concrete) was poured into a pair of steel molds (each mold with a dimension of $12.5 \times 25 \times 10 \mathrm{~cm}$ ) equipped with a semi-automatic compaction machine. The two concrete blocks were then tamped by the machine with a pressure of $10 \mathrm{MPa}$. After demolding, the specimens were initially air cured for a period of 24 hours, avoiding sunlight. After that the samples were immediately sprayed with water and covered with polyethylene sheet to prevent moisture loss, and cured for another 28 days. After 28 days, the concrete samples were ready for further testing.

\section{2) Product test method}

The physical and chemical properties of the interlocking concrete blocks mixed with NMF were analyzed according to the testing methods summarized in Table IV.

\begin{tabular}{ll}
\multicolumn{2}{c}{ TABLE IV: PRODUCT TEST METHOD } \\
\hline \multicolumn{1}{c}{ Testing } & \multicolumn{1}{c}{ Method } \\
\hline Compressive strength & TIS 109-2517 [23] and ASTM C140 \\
& {$[24]$} \\
Water absorption & TIS 109-2517 and ASTM C140 \\
Leachability & Waste Extraction Test (WET), Thailand \\
& {$[25]$} \\
\hline
\end{tabular}

TIS = Thai Industrial Standard

ASTM = American Society for Testing and Materials

\section{a) Water absorption}

After curing the specimens for 28 days, the water absorption was tested to get the average values from three specimens of each mix. Firstly, the specimens were immersed in water at $16-27^{\circ} \mathrm{c}$ (or room temperature) for 24 hours. After immersing, the specimens were wiped with dry cloth to make surface dry, then weighed and recorded. Next, the specimens were placed for dry heating in an oven at $110-115^{\circ} \mathrm{c}$ for 24 hours. After oven drying, the specimens were allowed to cool down at room temperature, the re-weighed and recorded.

\section{b) Compressive strength}

After curing specimens for 28 days, the test of compressive strength was conducted to obtain average values from three specimens of each mix. The compressive strength was determined by using a Universal Testing Machine (UTM) with a load capacity of $1000 \mathrm{kN}$. Before compression testing, gypsum capping was required in order to smoothen the surface of the concrete block specimens. The assigned loading was then applied to the nominal area of the gypsum-capped surface. The compressive strength of each specimen was calculated from the maximum load divided by the total area of the gypsum-capped surface.

c) Leachability

The leachability of heavy metals in the interlocking concrete block specimens was evaluated using the Waste Extraction Test (WET) according to the Notification of Ministry of Industry, Industrial Waste Disposal B.E. 2548 (2005) [25]. After completing the compression testing, the samples were crushed to pass through $2 \mathrm{~mm}$ sieve (no. 10). A solid crushed sample was put into $0.2 \mathrm{M}$ sodium citrate extraction solution ( $\mathrm{pH} 5.0 \pm 0.1$ ) at a solid to liquid ratio of $1: 10$. The sample was extracted for 48 hours in a rotary mixer. The leachate was then filtered through a $0.45 \mu \mathrm{m}$ membrane filter. The target heavy metals present in the leachate were analyzed using an inductively coupled plasma-optical emission spectral photometer (ICP).

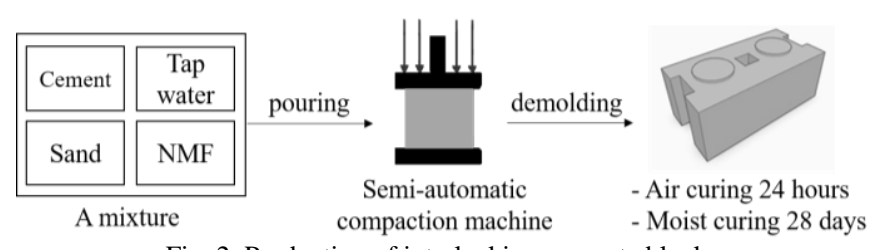

Fig. 2. Production of interlocking concrete block.

\section{RESULTS AND DISCUSSION}

\section{A. Density and Water Absorption}

In Fig. 3, it can be seen that the density of all interlocking concrete block specimens gradually decreased when increasing the contents of NMF residue. The density of NMF-5\%, NMF-10\%, NMF-15\% and NMF-20\% were $0.46 \%, 2.4 \%, 3.45 \%$ and $4.5 \%$ lower than the controlled mix, respectively. The reduction of density in the NMF-interlocking concrete block is directly attributed to the fact that the weight and specific gravity of NMF residue are lower than those of natural fine aggregate (sand) (see Table II). Saengpaeng [20] reported a similar result that the density of concrete and mortar mixed with NMF residue as fine aggregates was lower than that of the controlled concrete and mortar (without NMF), and the density decreased with increasing contents of NMF. Besides, the very fine size of NMF particles (see also Fig. 1) can affect the decreased density of concrete blocks. According to the study on the effect of particle sizes on packing density of fine aggregate, it has been reported that with the incorporation of finer aggregate, the packing density decreases significantly, meaning that the structure has higher porosity as the 
percentage of fine aggregate in the replacement increased [26]. However, it was obviously found in this study that the $\mathrm{NMF}$ particles were more prone to agglomeration, giving an uneven particle distribution of very fine NMF particles within the concrete block which could result in a more porous structure similar to that of Lee et al. [26].

The results of water absorption for the interlocking blocks at 28 days are presented in Fig. 3. It indicates that the interlocking concrete blocks containing NMF had higher water absorption values when comparing to the controlled samples, and the water absorption increased with increasing NMF contents. This is due to high water absorption capacity of NMF material itself (see Table II), and could be attributed to the poor packing density (or high porosity) of aggregates as discussed above. Based on Thailand Community Product Standard (TCPS) 602, the acceptable maximum value of water absorption in an interlocking concrete block is recommended at $11 \%$. The results here show that the water absorption of all interlocking concrete blocks satisfied the recommendation of the standard.

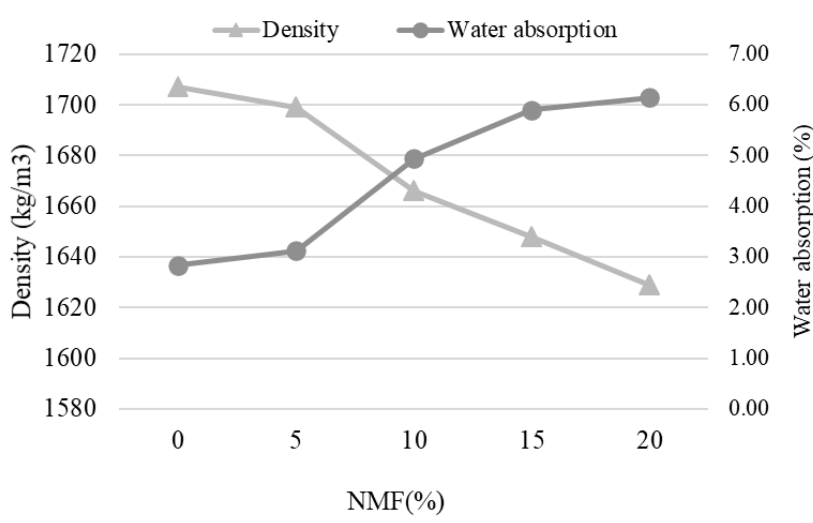

Fig. 3. Density and water absorption of interlocking block at 28 days.

\section{B. Compressive Strength}

The 28-day compressive strength of the controlled interlocking specimens and interlocking concrete block specimens mixed with different percentages of NMF residue are shown in Fig. 4. It can be seen that compressive strength of all specimens with NMF residue were slightly and gradually lower than the controlled specimens. This result is in line with the results of density and water absorption mentioned above. The low density and higher water absorption are generally associated with lower compressive strength results. It is found that the compressive strengths of NMF-5\%, NMF-10\%, NMF-15\% and NMF-20\% were $14.3 \%, 21.3 \%, 51.4 \%$ and $53.2 \%$ lower than the controlled specimens, respectively. The results are clear that the more NMF content is added, the lower compressive strength value is achieved. It can be stated that the NMF residue used as a partial sand substitute has a detrimental effect on the properties of interlocking concrete block in terms of compressive strength. However, at 5\% and 10\% NMF, interlocking concrete blocks investigated in this study still provided compressive strength higher than 2.5 $\mathrm{MPa}$, the recommended value for non-load bearing concrete block in TCPS 602 by the Ministry of Industry.

For the decrease in compressive strength as the NMF replacement increased, it could be attributed to a weak bonding between cement paste and the NMF residue, which led to the reduction of the overall specimen strength. The results in this study are in agreement with the previous research [20], [27].

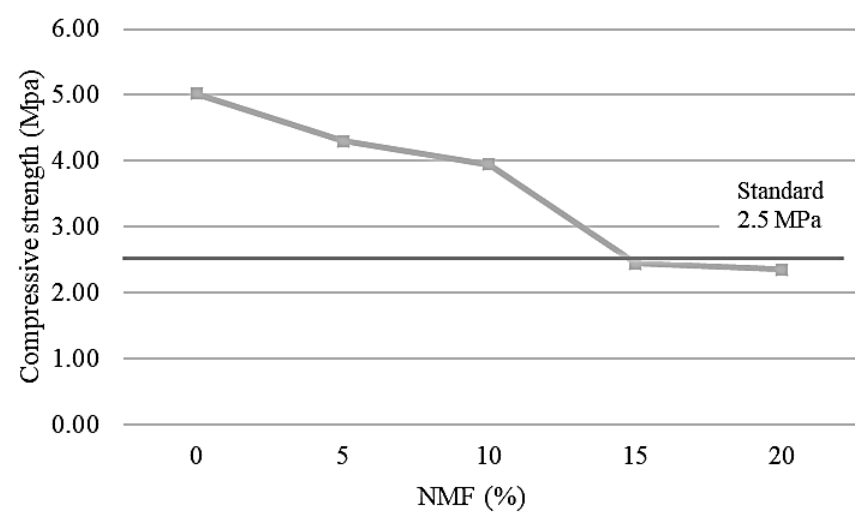

Fig. 4. Compressive strength of interlocking block at 28 days.

In addition, the existence of heavy metals in the waste residue can be another reason for a degradation of mechanical performance of concrete. It is well known that the main compound acting in cement hardening, and accountable for strength development and durability are calcium silicate hydrate $(\mathrm{C}-\mathrm{S}-\mathrm{H})$. Heavy metals remaining in the waste residue (i.e. NMF) can cause a distraction in the hydration reaction of cement and preventing the formation of an effective C-S-H gel, which causes a lack of effective encapsulation and decrease the strength of concrete [28], [29]. Therefore, the metal residues and the content of NMF probably influenced the reduction of the compressive strength as shown in Fig. 4.

\section{Leachability}

Due to the lack of national regulation to evaluate leaching from concrete products, Waste Extraction Test (WET) according to the Notification of Ministry of Industry on Industrial Waste Disposal of Wastes or Unusable B.E. 2548 (2005) was applied for waste residue (NMF) and all interlocking concrete block specimens. In this study, $5 \%$ and $10 \% \mathrm{NMF}$ interlocking concrete blocks at 28 days-curing time were selected to be tested for the leachability of heavy metals as both NMF replacement rates met the compressive strength of TCPS 602 as discussed above (see Fig. 4). The target heavy metals, namely barium $(\mathrm{Ba})$, copper $(\mathrm{Cu})$, lead $(\mathrm{Pb})$, Nickle $(\mathrm{Ni})$ and zinc $(\mathrm{Zn})$, were selected for testing based on Soluble Threshold Limit Concentration (STLC) listed in Appendix II of the Thailand Notification of the Ministry of Industry, Industrial Waste Disposal of Wastes or Unusable B.E. 2548 (2005), and their high contents detected in the NMF residue (see Table I). The results of leaching test on the specimens in Table $\mathrm{V}$ show that $\mathrm{Ba}, \mathrm{Pb}$, and $\mathrm{Ni}$ could not be detected in the leachate solution at $5 \%$ and $10 \%$ of NMF interlocking block specimens. Only $\mathrm{Zn}$ and $\mathrm{Cu}$ were detected in both leachate solutions. The concentration of $\mathrm{Zn}$ in leachate was well below the STLC limit $(250 \mathrm{mg} / \mathrm{l})$. But for $\mathrm{Cu}$, the concentration level still exceeded the limit value of $25 \mathrm{mg} / 1$ for both replacement rates at $5 \%$ and $10 \% \mathrm{NMF}$. In addition, the leaching of $\mathrm{Cu}$ at NMF-10\% is relatively higher than that of $\mathrm{Cu}$ at NMF-5\%. According to the results and discussion above and the study by Mahdikhani and 
Khanban [29], the reason could be the lack of effective encapsulation of the waste materials, high heavy metal interference in cement hydration, which also caused a decrease in density and strength. So, the increasing of the percentage replacement of NMF in specimen causes a greater release of $\mathrm{Cu}$ as a consequence of the higher permeability and higher water absorption.

TABLE V: HEAVY METAL CONCENTRATIONS OF NMF INTERLOCKING CONCRETE BLOCK

\begin{tabular}{|c|c|c|c|c|}
\hline Element & $\begin{array}{r}\text { NMF Res. } \\
(\mathrm{mg} / \mathrm{L})\end{array}$ & $\begin{array}{r}5 \% \mathrm{NMF} \\
(\mathrm{mg} / \mathrm{L})\end{array}$ & $\begin{array}{r}10 \% \text { NMF } \\
(\mathrm{mg} / \mathrm{L})\end{array}$ & $\begin{array}{r}\text { Regulation } \\
\text { limit }^{2}\end{array}$ \\
\hline $\mathrm{Ba}$ & 0.49 & ND & ND & 100 \\
\hline $\mathrm{Cu}$ & 58.70 & 37.40 & 46.70 & 25 \\
\hline $\mathrm{Pb}$ & 0.06 & ND & ND & 5 \\
\hline $\mathrm{Ni}$ & 0.13 & ND & ND & 20 \\
\hline $\mathrm{Zn}$ & 12.70 & 0.82 & 0.16 & 250 \\
\hline
\end{tabular}

$\mathrm{ND}=$ Not detectable

$1=$ NMF Residue

$2=$ Notification of Ministry of Industry of disposal of wastes or unusable

Nevertheless, if comparing between the specimens and the $\mathrm{NMF}$ residue (raw material), the amount of heavy metals (Ba, $\mathrm{Cu}, \mathrm{Pb}, \mathrm{Ni}$ and $\mathrm{Zn}$ ) leached out from all specimens were much lower than the original NMF material (see Table V). It is obvious that most heavy metals in all specimens were immobilized well in the concrete blocks.

Due to the presence of high $\mathrm{Cu}$ content in the leachates as described above, it was hypothesized that the addition of Portland cement could be more effective for immobilization of $\mathrm{Cu}$ in the specimens. Fig. 5 shows the results of cement addition to NMF-5\% and NMF-10\% interlocking concrete block specimens. The results show that the leachability of $\mathrm{Cu}$ instantly decreased from the initial mix when adding $3 \%$ cement content. It is noted that the leaching of $\mathrm{Cu}$ is relatively steady with increasing cement content more than $3 \%$. The leachability of $\mathrm{Cu}$ from NMF-10\% interlocking concrete blocks were higher than that from NMF-5\% concrete blocks for all percentages of cement addition. The concentration levels of $\mathrm{Cu}$ in all leachates were well below the STLC limit of $25 \mathrm{mg} / 1$.

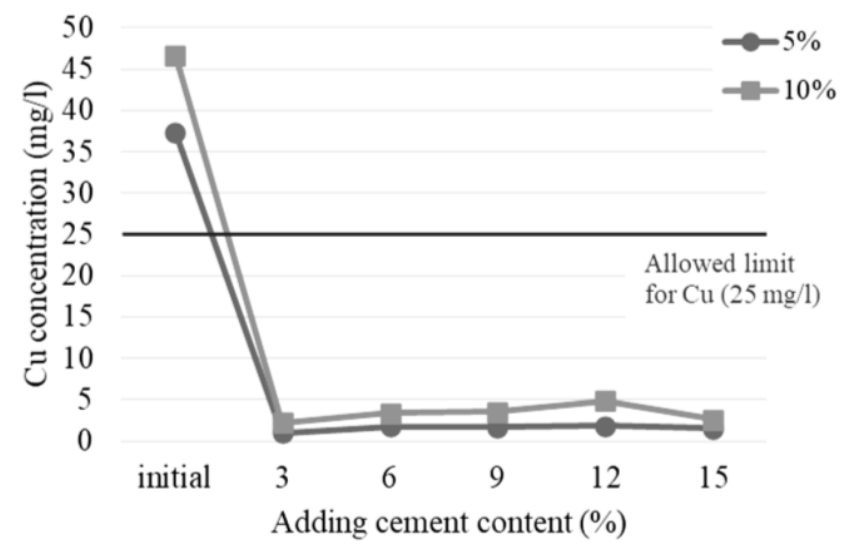

Fig. 5. Levels of $\mathrm{Cu}$ concentration with addition of cement.

Considering the results of cement addition, it can be explained that the content of cement in the sample affected the leachability of metals. High cement content provides more chances to coat the individual NMF particle. This indicates that the metal ions have a higher opportunity to be bound with the more formation of hydration products in solid matrix [30]. The more cement content is used in the sample, the lower $\mathrm{Cu}$ leachability becomes. This means that higher cement content was more effective for encapsulation of metal species. Therefore, the increment of cement has a positive effect to reduce the leachability of metal species.

\section{CONCLUSION}

This study examined the suitability and ability of NMF recycled as a sand replacement in interlocking concrete blocks. Physical (density and water absorption) and mechanical property (compressive strength) of the specimens were firstly evaluated and the selected samples were further analyzed for an environmental impact using leachability test. All findings of this study can be concluded that the use of recycled NMF from waste printed circuit boards as a substitute for fine aggregate to produce interlocking concrete blocks is technically feasible.

However, in order to promote the recycling or utilization of NMF residues for manufacturing of interlocking concrete blocks in a manner that is both technically and economically feasible, complying with the standards and yet safe to human health and the environment, several factors have to be taken into account, including waste use permission, product standards, environmental impact and cost effectiveness. Regarding the results of this study, percentage of waste replacement, water absorption, compressive strength for non-load bearing concrete, and heavy metal leachability have all been investigated, analyzed and discussed. At this stage, it can be suggested that $5 \% \mathrm{NMF}$ and $10 \% \mathrm{NMF}$ replacement with adding 3\% cement content, meeting all products standards requirements, including heavy metal leachability standard, should be furthered considered for cost-benefit analysis and then compared to the commercial product price available in the market.

\section{CONFLICT OF INTEREST}

The authors declare no conflict of interest.

\section{AUTHOR CONTRIBUTIONS}

S. Pianchaiyaphum conducted the research and experimental measurement, and analyzed the data. S. Kwonpongsagoon analyzed the data and wrote the paper. P. Kanchanapiya and C. Tuakta provided comments and suggestions on the manuscript. All authors had approved the final version.

\section{ACKNOWLEDGMENT}

This research work was financially supported by the Center of Excellence on Environmental Health and Toxicology (EHT), Science \& Technology Postgraduate Education and Research Development Office (PERDO), Ministry of Education, Thailand.

\section{REFERENCES}

[1] C. P. Baldé, V. Forti, V. Gray, R. Kuehr, and P. Stegmann, "The global e-waste monitor - 2017", United Nations University (UNU), International Telecommunication Union (ITU) \& International Solid Waste Association (ISWA), Bonn/Geneva/Vienna. 
[2] Pollution Control Department Thailand, Thailand State of Pollution Report 2018, 1st ed. Bangkok, Thailand, 2018, ch. 3, pp. 35-39.

[3] A. Bernardes, I. Bohlinger, D. Rodriguez, H. Milbrandt, and W. Wuth, "Recycling of printed circuit boards by melting with oxidising/reducing top blowing process," in Proc. 126th TMS Annual, vol. 7, pp. 363-375, 1997.

[4] M. Tatariants, S. Yousef, R. Sidaraviciute, G. Denafasa, and R. Bendikieneb, "Characterization of waste printed circuit boards recycled using a dissolution approach and ultrasonic treatment at low temperatures," The Royal Society of Chemistry, vol. 7, pp. 37729-37738, 2017.

[5] J. Li, H. Lu, J. Guo, Z. Xu, and Y. Zhou, "Recycle technology for recovering resources and products from waste printed circuit boards," Environmental Science and Technology, vol. 41, pp. 1995-2000, 2007.

[6] H. M. Veit, C. Nichele, and S. Janine, "Use of gravity separation in metals concentration from printed circuit board scraps," Esc, vol. 67, no. 1, 2014.

[7] R. Cayumil, R. Khanna, R. Rajarao, P. S. Mukherjee, and V. Sahajwalla, "Concentration of precious metals during their recovery from electronic waste," Waste Management, vol. 57, pp. 121-130, 2016.

[8] C. Hagelüken, "Recycling of electronic scrap at Umicore's integrated metals smelter and refinery," Erzmetall, vol. 59, pp. 152-161, 2006.

[9] S. Yousef, M. Tatariants, R. Bendikiene, and G. Denafas, "Mechanical and thermal characterizations of non-metallic components recycled from waste printed circuit boards," Journal of Cleaner Production, vol. 167, pp. 271-280, 2017.

[10] K. Premrudee, "E-waste: Technology of printed circuit board management," Bangkok: Thai Effect Studio, 2011.

[11] S. Tesanan, "Stabilization and solidification of non-valuable residue from waste printed circuit boards," M.S. thesis, Faculty of Public Health, Mahidol Uni., Bangkok, Thailand, 2016.

[12] J. Sawanya and K. Premrudee, "The recycling of non-metallic fractions from printed circuit board waste as a FRP (Fiber Reinforced Plastic) furniture product," M.S. thesis, Faculty of Public Health, Mahidol Uni., Bangkok, Thailand, 2015.

[13] J. Guo, Q. Rao, and Z. Xu, "Application of glass-nonmetals of waste printed circuit boards to produce phenolic moulding compound," Journal of Hazardous Materials, vol. 153, pp. 728-734, 2008.

[14] J. Guo, J. Guo, S. Wang, and Z. Xu, "Asphalt modified with nonmetals separated from pulverized waste printed circuit boards," Environ. Sci. Technol., vol. 43, no. 2, pp. 503-508, 2009.

[15] Directive 2012/96/EC of the European Parliament and of the Counci of 22 November 2008 on waste electrical and electronic equipment Journal of the EU L 312, 3 .

[16] K. Premrudee, P. Waraporn, J. Sawanya, and K. Suphaphat, "Recycling of non-metallic powder from printed circuit board waste as a fille material in a fiber reinforced polymer," Environment Protection Engineering, vol. 41, pp. 151-166, 2015

[17] J. Guo, J. Li, Q. Rao, and Z. Xu, "Phenolic molding compound filled with nonmetals of waste PCBs," Environ. Sci. Technol., vol. 42, pp. 624-628, 2008

[18] Y. Zheng, Z. Shen, S. Ma, C. Cai, X. Zhao, and Y. Xing, "A novel approach to recycling of glass fibers from nonmetal materials of waste printed circuit boards," Journal of Hazardous Materials, vol. 170, pp 978-982, 2009.

[19] T. Kovacevic, J. Rusmirovic, N. Tomic, M. Marinović-Cincović, Z. Kamberović, M. Tomić, and A. Marinkovic, "New composites based on waste PET and non-metallic fraction from waste printed circuit boards: Mechanical and thermal properties," Composites Part B, Engineering, vol. 127, pp. 1-14, 2017.

[20] P. Saengpaeng, "Use of recycled non-metallic powder reclaimed from printed circuit board waste as fine aggregate in concrete," M.S. thesis, Faculty of Engineering, Kasetsart Uni., Bangkok, Thailand, 2017.

[21] Y. Chen, Y. Zhang, J. Yang, S. Liang, K. Liu, K, Xiao, H. Deng, J. Hua, and B. Xiao, "Improving bromine fixation in co-pyrolysis of non-metallic fractions of waste printed circuit boards with Bayer red mud," Science of the Total Environment, vol. 639, pp. 1553-1559, 2018.

[22] Y. Shen, "Effect of chemical pretreatment on pyrolysis of non-metallic fraction recycled from waste printed circuit boards," Waste Management, vol. 76, pp. 537-543, 2018 .
[23] TIS 109, "Standard for Sampling and testing concrete masonry units," Thai Industrial Standards Institute, 1974.

[24] ASTM C140 / C140M-20a, Standard Test Methods for Sampling and Testing Concrete Masonry Units and Related Units, ASTM International, West Conshohocken, PA, 2020

[25] Notification of Ministry of Industry of Disposal of Wastes or Unusable B.E. 2005 (2548)

[26] G. Lee, C. S. Poon, Y. L. Wong, and T. C. Ling, "Effects of recycled fine glass aggregates on the properties of dry-mixed concrete blocks," Construction and Building Materials, vol. 38, pp. 638-643, 2013.

[27] H. S. Sureshchandra, G. Sarangapani, and B. G. N. Kumar, "Experimental Investigation on the Effect of replacement of sand by quarry dust in hollow concrete block for different mix proportions," International Journal of Environmental Science and Development, vol. 5, pp. 15-19, 2014

[28] R. Malviya and R. Chaudhary, "Factors affecting hazardous waste solidification/stabilization: A review," Journal of Hazardous Materials, vol. 137, pp. 267-276, 2006

[29] M. Mahdikhani and M. R. Khanban, "Utilization of industrial waste residue containing heavy metals as a substitute for fine aggregates," Construction and Building Materials, vol. 221, pp. 772-786, 2019.

[30] S. S. G. Hashemi, H. B. Mahmud, T. C. Ghuan, A. B. Chin, C. Kuenzel, and N. Ranjbar, "Safe disposal of coal bottom ash by solidification and stabilization techniques," Construction and Building Materials, vol. 197, pp. 705-715, 2019

Copyright $\odot 2021$ by the authors. This is an open access article distributed under the Creative Commons Attribution License which permits unrestricted use, distribution, and reproduction in any medium, provided the original work is properly cited (CC BY 4.0).

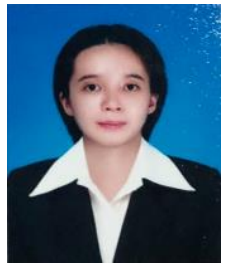

Sawitri Pianchaiyaphum obtained her BSc.in environmental health science from Mahidol University, Thailand. She is currently a master's student in environmental technology program at Mahidol University, a scholarship holder from the Center of Excellence on Environmental Health and Toxicology (EHT), Science \& Technology Postgraduate Education and Research Development Office (PERDO), Ministry of Education, Thailand. Her research area is utilization of electronic waste.

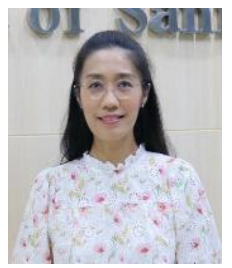

Suphaphat Kwonpongsagoon is a corresponding author of this article. She received her $\mathrm{Ph}$. D in civil and environmental engineering from the University of New South Wales (UNSW), Australia. She is currently an assistant professor at the Department of Sanitary Engineering, Faculty of Public Health, Mahidol University, Thailand. Her specialization and research interest include waste management and analytical tools for environmental management and sustainability such as mathematical material flow analysis (MMFA), life cycle assessment (LCA), and health risk assessment (HRA).

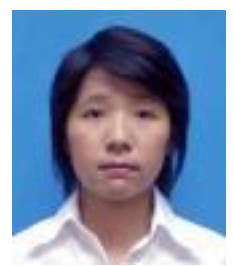

Premrudee Kanchanapiya graduated from graduate school of natural science \& technology, Division of global environmental sci. and engineering, Kanazawa University, Japan in 2005. She has worked as research at National Metal and Materials Technology Center, Thailand. Her main research interests are in waste management and utilization, emerging pollutant monitoring/treatment and life cycle assessment.

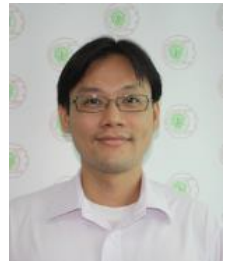

Chakrapan Tuakta received his Ph.D. in Structures and Materials from the Department of Civil and Environmental Engineering, Massachusetts Institute of Technology, USA. He is currently an assistant professor at the Department of Civil Engineering, Kasetsart University, Thailand. His research interests include green construction materials, composites for structural strengthening, and material modeling. 